\title{
The Elution of Alkaloids from SE-Sephadex
}

\author{
CARL OLOF BJöRLING and BARBRO WILLMAN-JOHNSON
}

Research laboratories, Pharmacia Ltd., Uppsala, Sweden

\begin{abstract}
Experiments show some properties of the new cation exchange gel, SE-Sephadex. Alkaloidal and similar ions, for example, are more readily eluted from the gel than from ordinary cation exchange resins. This may be used in analytical separations.
\end{abstract}

rganic ions of medium or high molecular weight are often difficult to elute, once they have been taken up by a cation exchange resin with a normal network. It has been shown (Refs. ${ }^{1}, 2$ ) that the elution is easier if the degree of crosslinking is low and if the eluting acid contains $70 \%$ of an organic solvent, e.g. ethanol, methanol, or acetone instead of water alone. However, even then the volume of the elutriant is large compared with the volume of the resin bed and still larger than the volume calculated necessary from stoichiometry. The resin holds the great ion not only by ionic forces but also by non specific adsorption.

Now, a new kind of ion exchanger shows a different mode of action. It is SE-Sephadex, a strong ion exchanger which is a sulphoethyl ether derivative of Sephadex recently introduced by Pharmacia (Ref. ${ }^{3}$ ). Three examples may serve as illustrations of the properties of different ion exchange columns.

1. If you let $10 \mathrm{mg}$ of an alkaloidal ion with the molecular weight 300 pass a $4 \times 40 \mathrm{~mm}$ column of an ordinary uncharged Sephadex gel it is only slightly retarded. The cation appears in the effluent after $0.2 \mathrm{ml}$, i.e. immediately after the void volume, and it has left the bed entirely after $0.5 \mathrm{ml}$.

2. If you substitute the Sephadex for a sulphoethyl dextran gel (SE-Sephadex) with the same degree of crosslinking the alkaloidal ion is retained quantitatively but it can be eluted with $5-15 \mathrm{ml}$ of $0.1 \mathrm{~N}$ hydrochloric acid, aqueous or, in some cases in $70 \%$ alcohol. The minimum theoretical value is $3 \mathrm{ml}$ of the acid.

3 . If you make the experiment with ion exchange resins the elution proceeds more slowly. Dowex $50 \times 1$, e.g., requires $10-25 \mathrm{ml}$ of $1 \mathrm{~N}$ hydrochloric acid in $70 \%$ alcohol ${ }^{1}$, and from the types of Dowex, e.g. $50 \times 16,50 \times 12$, or $50 \times 8$, which have a denser network, the elution is still slower or even incomplete. 
Most alkaloids can also be eluted with $0.1 \mathrm{~N}$ sodium chloride solution from the SE-Sephadex column which is seldom possible for the resin exchangers.

Kinetic experiments have shown that alkaloidal cations are released from the SE-Sephadex quite rapidly at room temperature even by very weak hydrochloric acid or sodium chloride solution. With decreasing excess the elution slows down and the equilibrium yield decreases from $100 \%$, when the excess of the elutriant is larger than 20-30 times, down to a few per cent when the elutriant is equivalent to $40 \%$ of the alkaloid.

\section{EXPERIMENTAL}

Material. Sulpho-ethyl dextran gel (SE-Sephadex C-25, 865/1 B op. 104) was allowed to swell in $0.1 \mathrm{~N}$ hydrochloric acid for $30 \mathrm{~min}$ and was freed from fine particles by decantation. The gel was washed free from chloride and used in columns $4 \times 40 \mathrm{~mm}$. The capacity of the air dried material was 2.0 mequiv./g. Many of the experiments were performed with DMABF, 9-(4-dimethylamino-benzylidene)-fluorene ethyl tosylate, which is a salt of a quaternary base with a fairly great molecule (mol.wt. of the cation 326.44). The capacity of the column for DMABF was $140 \mathrm{mg}$ which corresponds to 0.28 mequiv.

Elution. DMABF is eluted very slowly with aqueous solutions. $5 \mathrm{ml}$ of $0.1 \mathrm{~N}$ or $0.2 \mathrm{~N}$ hydrochloric acid released only $0.4 \%$ from the saturated column, and five more volumes yielded the same small percentage. However, all DMABF was eluted in a single eluate of $5 \mathrm{ml}$ of $0.1 \mathrm{~N}$ hydrochloric acid in $70 \%$ ethanol. Thus, here the nature of the solvent is decisive. Figs. 1 and 2 show how DMABF is eluted by different electrolytes dissolved in water or aqueous ethanol.

In Figs. 3, 4 and 5 equivalent amounts of two compounds have "competed" for the hydrogen sites of three separate SE-Sephadex C-25 columns, which could take only half the applied quantity of ions. The three pairs of substances behaved quite differently

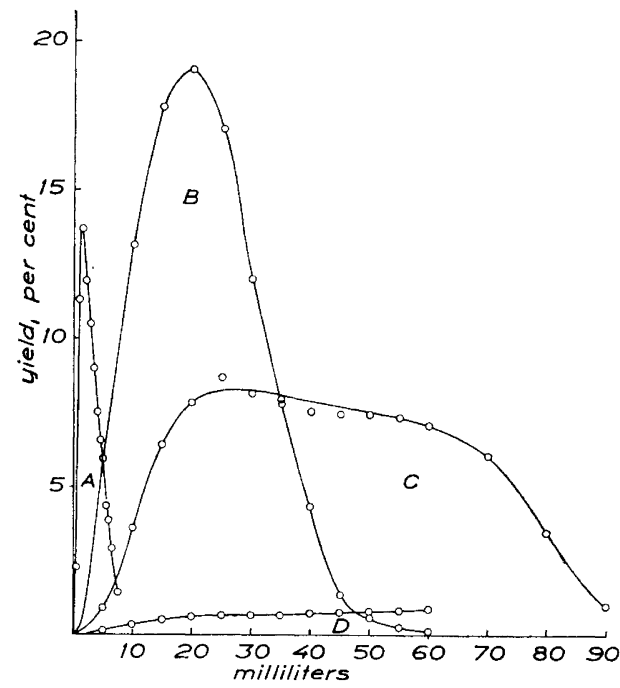

Fig. 1. $15 \mathrm{mg}$ of DMABF on a column of SE-Sephadex, $4 \times 40 \mathrm{~mm}$, is eluted with hydrochloric acid: A $0.1 \mathrm{M}$ in $70 \%$ alcohol, $\mathrm{B} 0.01 \mathrm{M}$ in $70 \%$ alcohol, $\mathrm{C} 0.01 \mathrm{M}$ in $50 \%$ alcohol, D $0.01 \mathrm{M}$ in $30 \%$ alcohol.

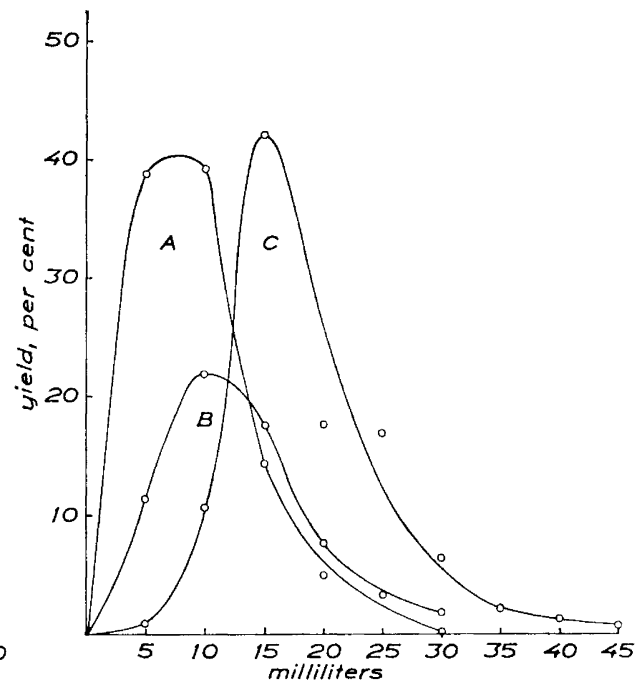

Fig. 2. $15 \mathrm{mg}$ of DMABF on a column of SE-Sephadex, $4 \times 40 \mathrm{~mm}$, is eluted with $0.01 \mathrm{M}$ solutions of a salt in $70 \%$ alcohol: A. $\mathrm{AlCl}_{3}$, B. $\mathrm{BaBr}_{2}$, C. $\mathrm{NaBr}$.

Acta Chem. Scand. 17 (1963) No. 10 


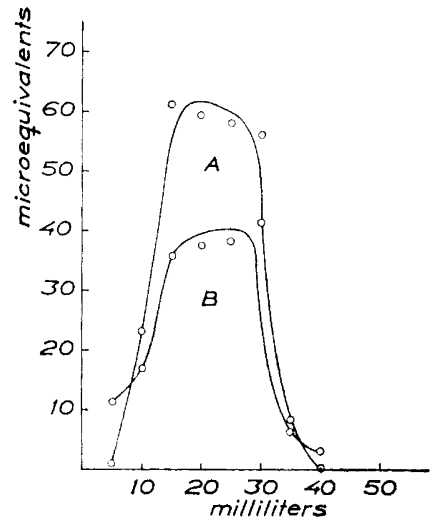

Fig. 3. $300 \mu$ equiv, of DMABF and of sodium bromide applied to a column of SE. Sephadex, $4 \times 40 \mathrm{~mm}$. Washing with 70 $\%$ alcohol: A. DMABE in the effluent, B. Sodium bromide in the effluent.

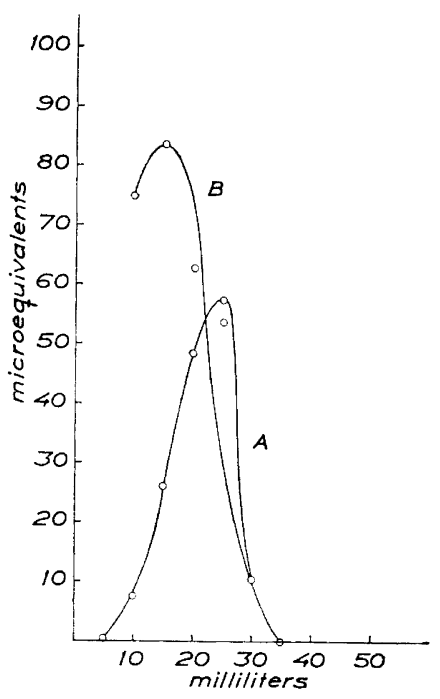

Fig. 4. 300 uequiv. of strychnine nitrate and of sodium chloride applied to a column of SE-Sephadex, $4 \times 40 \mathrm{~mm}$. Washing with water. A. Strychine nitrate, B. Sodium chloride.

In Fig. 3 the competitors are DMABF and sodium bromide in $70 \%$ ethanol. They appear in the effluent at the same time, but $90 \%$ of the DMABF goes through and only $65 \%$ of the sodium. In Fig. 4 strychnine nitrate and sodium chloride are applied to the column. Both cations appear in the effluent at the same time, but the recovery of the organic ion is only $50 \%$ compared with $90 \%$ of the sodium ions. In Fig. 5 calcium ions lag

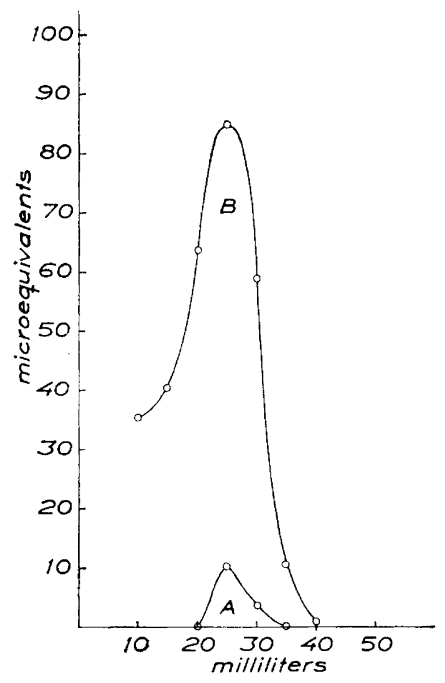

Fig. 5. $265 \mu$ equiv. of calcium chloride and of sodium bromide applied to a column of SE-Sephadex, $4 \times 40 \mathrm{~mm}$. Washing with water. A. Calcium chloride, B. Sodium bromide. 
ELUTION OF ALKALOIDS

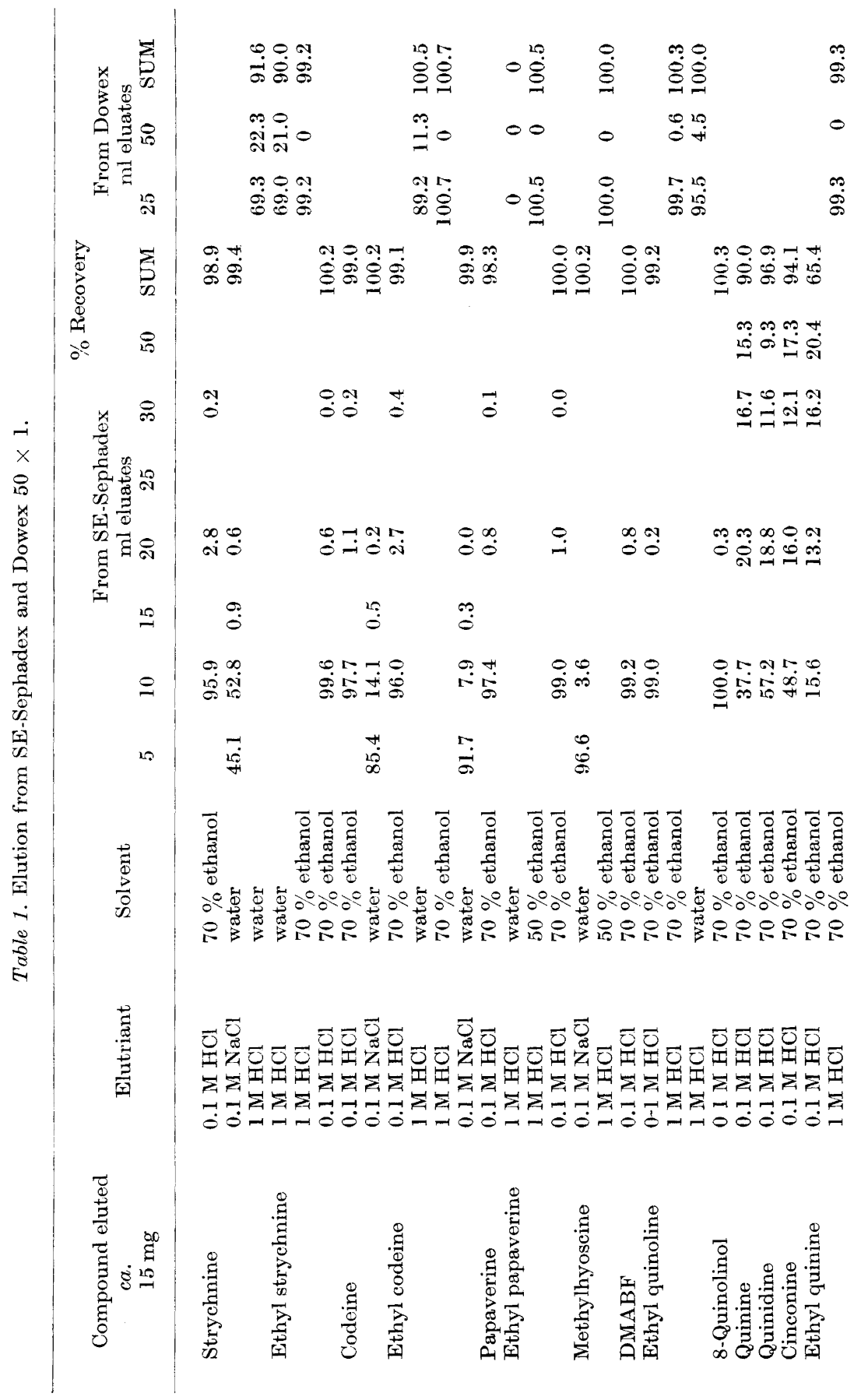

Acta Chem. Scand. 17 (1963) No. 10 


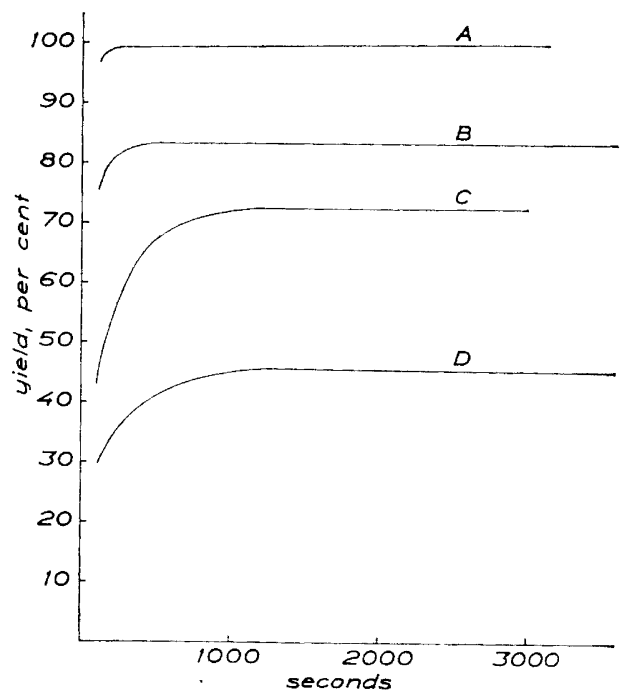

Fig. 6. SE-Sephadex saturated with strychnine shaken with $100 \mathrm{ml}$ of hydrochloric acid.

Curve Mg of strychnine

$\begin{array}{ll}\text { A } & 49.62 \\ \text { B } & 49.02 \\ \text { C } & 17.41 \\ \text { D } & 23.39\end{array}$

Molarity of acid

Quotient mequiv.

$\begin{array}{lc}0.05 & 91 \\ 0.01 & 19 \\ 0.001 & 5.3 \\ 0.0005 & 1.9\end{array}$

behind the sodium ions in the effluent. All the sodium is recovered there, but only $5 \%$ of the calcium.

As in ion exchange resins the calcium ion is hard to elute with sodium ion. From 19.4 mg of calcium chloride on a column, only $18 \%$ was eluted by $50 \mathrm{ml}$ of an $0.01 \mathrm{M}$ aqueous solution of sodium bromide, and $25 \mathrm{ml}$ of $0.1 \mathrm{M}$ sodium bromide to follow released only $28 \%$. (5.7 $\mathrm{ml}$ of $0.1 \mathrm{M}$ solution is equivalent to the whole calcium quantity).

Table 1 shows results of elution experiments from SE-Sephadex columns and - for comparison taken from Ref. ${ }^{1}$ - from Dowex $50 \times 1$, an ion exchange resin with a very low degree of cross-linking. From this resin the elution of big ions is easier than from other ion exchange resins. Some conclusions may be drawn from the table.

1. Some ions need alcoholic media for their elution. most do with water.

2. Elution from SE-Sephadex is by far easier than elution from the resin. In most cases $0.1 \mathrm{M}$ aqueous solutions of $\mathrm{HCl}$ or $\mathrm{NaCl}$ elute rapidly in quantities which are $2-3$ times of theory. Elution from Dowex $50 \times 1$ requires $10-20$ times more elutriant, and it is not possible without using $1 \mathrm{M}$ concentrations and - often - alcoholic media.

Kinetic experiments. Sulphoethyl-dextran gel C-25 was saturated with the free bases of codeine, lidocaine, strychnine, and choline by shaking. The excess alkaloids were washed away with appropriate solvents and the resulting product dried in vacuo. The content of alkaloids was determined after exhaustive elution with hydrochloric acid and was: of codeine 1.34, of strychnine 1.75 , of lidocaine 1.94 , and of choline $2.01 \mathrm{mequiv} / \mathrm{g}$ ion exchanger. The products did not lose any alkaloid on washing with water, alcohol etc.

$15-70 \mathrm{mg}$ of gel saturated with alkaloid was shaken with $100 \mathrm{ml}$ of hydrochloric acid or sodium chloride solutions of different concentrations. At specified intervals $5.00 \mathrm{ml}$ of the liquid was taken out and its alkaloidal content determined. Figs. 6 and 7 show some of the results. 


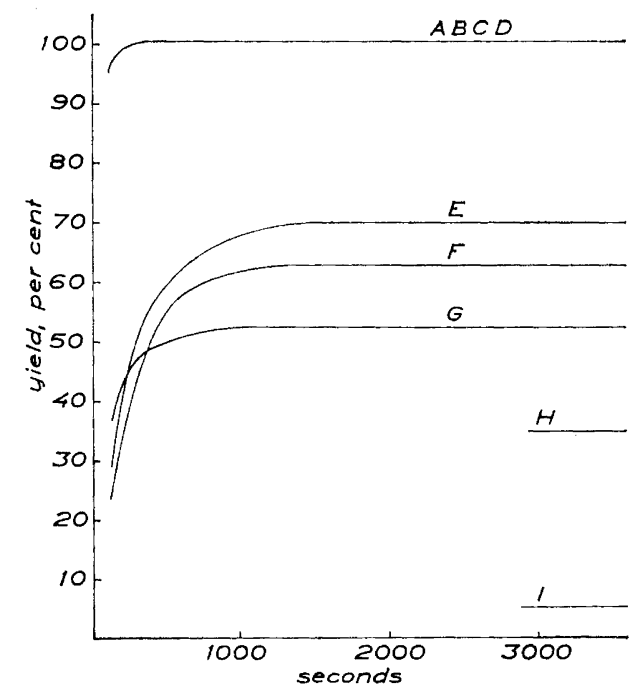

Fig. 7. SE-Sephadex saturated with codeine, lidocaine, strychnine or choline shaken with $100 \mathrm{ml}$ of sodium chloride solution.

$\begin{array}{clccc}\text { Curve } & \text { Alkaloid } & \begin{array}{c}\text { Mg of alkaloid } \\ \text { Sephadex }\end{array} & \begin{array}{c}\text { Molarity of } \\ \text { sodium chloride }\end{array} & \begin{array}{c}\text { Quotient mequiv } \\ \text { NaCl/alkaloid }\end{array} \\ \text { A } & \text { Codeine } & 36.07 & 0.025 & 74 \\ \text { B } & \text { Lidocaine } & 69.19 & 0.025 & 27 \\ \text { C } & \text { Strychnine } & 18.02 & 0.025 & 125 \\ \text { D } & \text { Choline } & 15.35 & 0.030 & 24 \\ \text { E } & \text { Strychnine } & 17.40 & 0.001 & 5.3 \\ \text { F } & \text { Codeine } & 34.82 & 0.001 & 3.0 \\ \text { G } & \text { Lidocaine } & 69.41 & 0.001 & 1.1 \\ \text { H } & \text { Choline } & 18.86 & 0.001 & 0.6 \\ \text { I } & \text { Choline } & 16.10 & 0.0005 & 0.4\end{array}$

\section{REFERENCES}

1. Berggren, A., Björling, C. O. and Willman-Johnson, B. Acta Chem. Scand. 12 (1958) 152.

2. Berggren, A. and Björling, C. O. Ibid. 11 (1957) 179.

3. von Hofsten, B. and Porath, J. Biochim. Biophys. Acta 64 (1962) 1.

Received July 12, 1963.

Acta Chem. Scand. 17 (1963) No. 10 